\title{
Minimally Invasive Surgery for Adolescent Idiopathic Scoliosis: Anterior and Posterior Techniques
}

\author{
Nicolas Amirghasemi1 ${ }^{1}$, Charlotte de Bodman ${ }^{2}$, Ayrat Syundyukov ${ }^{3}$, Stephen F Wendolowski ${ }^{4}$, Tamas F Fekete ${ }^{5}$ \\ Anne Tabard Fougère ${ }^{1 *}$, Vishal Sarwahi ${ }^{4}$ and Romain Dayer ${ }^{1,2}$ \\ ${ }^{1}$ Department of Child and Adolescent, Geneva University Hospitals, Switzerland \\ ${ }^{2}$ Pediatric Orthopedics and Traumatology Unit, Lausanne University Hospital, Switzerland \\ ${ }^{3}$ Orthopedic \&Endoprosthesis, The Federal Centre for Traumatology Orthopedic \& Endoprosthesis(Cheboksary, Russian Federation), Russia \\ ${ }^{4}$ Division of Pediatric Orthopedics, Cohen Children's Medical Center, USA
}

${ }^{5}$ Department of Spine Surgery and Neurosurgery, SchulthessKlinik, Switzerland

Submission: June 09, 2018; Published: July 18, 2018

*Corresponding author: Anne Tabard-Fougère, Pediatric Orthopedic Service, Department of Pediatrics, University Hospital Geneva, 6 rue Willy Donzé, 1211 Geneva 14, Switzerland, Tel: +41 2237291 64; Email: anne.tabard@hcuge.ch

\begin{abstract}
Purpose: Surgical gold standard for adolescent idiopathic scoliosis (AIS) is open posterior spinal instrumentation and fusion. This approach causes significant soft tissue disruption and paravertebral muscle detachment. This review attempts to provide an overview of the current state of knowledge of minimally invasive (MIS) surgery for AIS.

Methods: The results of MIS for adult scoliosis are briefly reviewed as the rationale for its application to AIS. A review of the two currently available MIS techniques for AIS is then given, including indications, surgical technique, and results in the literature.

Results: Thoracoscopic anterior spinal fusion and instrumentation (TASF) offers similar results and complication rates with decreased blood loss but is technically demanding and has limited indications. The posterior MIS technique seems to offer similar results and complication rates, decreased blood loss and shorter length of hospital stay, at the expense of a longer operative time.

Conclusion: Both TASF and posterior MIS are valid alternatives to the gold standard. They have proven similar results and short-term safety to open posterior fusion, with the added theoretical advantage of a less traumatizing exposure and improved cosmesis. While TASF has fallen out of favor due to its technical challenges, specific instrumentation and limited indications, posterior MIS does not suffer from these drawbacks. The limited amount of literature on this technique warrants studies with further follow-up, demonstrating its long-term safety before recommending its routine use.
\end{abstract}

Keywords: Adolescent idiopathic scoliosis; Minimally invasive surgery; Posterior spinal instrumented fusion; Thoracoscopic anterior spinal fusion; Instrumentation

\section{Introduction}

Adolescent idiopathic scoliosis (AIS) represents the majority $(51 \%)$ of the indications for scoliosis surgery at the pediatric age [1]. Untreated, this pathology results in a normal life expectancy [2,3], in productive and high-level functioning adults, with minimal physical impairment other than decreased body satisfaction and back pain [4]. Surgical treatment is usually indicated for major curves exceeding $40^{\circ}$ in growing adolescents, or $45^{\circ}$ in skeletally mature patients [5-8]. Its main purposes are to achieve a solid spinal fusion mass to prevent curve progression and to obtain three-dimensional correction of the deformity, while preserving balance in the coronal, sagittal, and axial planes [9].

Operative treatment has drastically evolved over the last century, from posterior Harrington instrumentation and casting, which was associated with high failed fusion rates, poor deformity correction, and the need for prolonged bed rest. Anterior thoracoscopic and miniopen approaches were later developed, which resulted in significant curve correction 
and high fusion rates [10]. Posterior fusion with segmental instrumentation, which is the current standard technique, has led to an improvement of deformity correction in the frontal and sagittal planes, together with a solid spinal arthrodesis and low complication rate [11-13].

Despite reproducible good outcomes, the standard open posterior approach requires extensive muscle dissection and soft tissue disruption, and is consequently associated with significant blood loss, postoperative pain, prolonged recovery, and a long midline scar $[12,14]$. In an effort to decrease this approach-related morbidity, a minimally invasive surgery (MIS) technique for posterior spinal fusion has been recently proposed for AIS [15]. Although promising, this posterior MIS technique for the treatment of adolescent deformity is far from being widely recognized, with currently very limited evidence to support its routine use [14].

This review aims to provide an overview of the current state of knowledge of MIS for AIS. We first briefly review the results of MIS for adult idiopathic and degenerative scoliosis, which provide the rationale for its application to the pediatric population. We then describe the indications, surgical technique, and results of thoracoscopic anterior spinal fusion and instrumentation (TASF), which is currently the only MIS alternative to the posterior MIS technique for AIS, despite its fading out. A detailed review of the posterior MIS technique for AIS is then provided, including technique, indications, and results in the current literature.

\section{Minimally Invasive Surgery for Adult Scoliosis}

Surgery for adult spinal deformity is a challenging procedure, due to a combination of patient- and intervention-related factors. Patients have medical comorbidities, physical deconditioning due to pain and bed rest, decreased bone mineral density, a stiff spine deformity, and distorted vertebral anatomy. The surgery itself is extensive, involving long spine fusion with instrumentation and osteotomies, and most often interbody fusion or an anterior approach to obtain a $360^{\circ}$ fusion [16]. Unsurprisingly, reported complication rates are significant, even in experienced hands, with $52 \%$ of patients affected by a perioperative complication ( 6 weeks), 43\% by a delayed complication (2 years) [17], and a postoperative mortality (30 days) of $2.4 \%$ [18]. Therefore, the safety of adult spine deformity surgery represents a major challenge, and the modern MIS technique has emerged in an attempt to lessen its morbidity in the aging population.

To date, most MIS techniques for degenerative and adult idiopathic scoliosis have combined a lateral interbody fusion, either with posterior percutaneous pedicle screw insertion in so-called circumferential MIS (cMIS), or with traditional open posterior surgery in so-called hybrid surgery [19-27]. These less invasive techniques have proven useful for adult spine deformity, with reduced complication rates compared to conventional open techniques, but also appear to be less effective for the correction of severe and/or fixed sagittal and coronal plane deformities [28].
Adolescent spine deformity is generally considered less rigid than adult and is thus theoretically more amenable to standalone MIS techniques. The pediatric spine, because of its inherent flexibility and ability to fuse, is theoretically ideal for MIS. Given the positive results obtained with MIS to treat adult spine pathologies, including deformities, the next logical step is the application of less invasive surgical techniques to the treatment of spine deformity at the pediatric age, AIS in particular.

\section{Thoracoscopic Anterior Spinal Fusion and Intrumentation} for Adolescent Idiopathic Scoliosis

During the nineties, thoracoscopic approaches were increasingly used in spine surgery [29-31]. The first thoracoscopic instrumentation and fusion for idiopathic scoliosis was performed in October 1996 [30,32]. The main thoracic curve pattern, Lenke type 1 , is the most common in operative AIS $[33,34]$. Although posterior spinal segmental instrumentation and fusion is considered the gold standard, open anterior surgery (thoracotomy) is associated with improved sagittal correction and saving of an average of 2.5 to 4 distal lumbar levels in prospective studies [9,35]. Additionally, the diskectomies performed in anterior correction of thoracic curves theoretically allow for better coronal correction [29], though two prospective studies found no significant difference in major curve correction compared to posterior surgery $[9,35]$. The main disadvantages of open anterior fusion are diminished postoperative pulmonary function, which persists at 2 years follow-up, and transient shoulder girdle dysfunction [9,36-38]. A few centers have contributed to develop a thoracoscopic technique for anterior instrumentation and fusion, in an effort to minimize the anterior approach-related morbidity. These techniques have indeed been shown to have less effect on pulmonary and shoulder girdle function postoperatively [36-40].

\section{Preoperative planning and patient selection}

TASF for AIS is indicated in Lenke type 1 (main thoracic) curves $[29,34]$ that require at most 8 segments of fusion within the boundaries of T4 and L1 $[12,41]$. While the Cobb end vertebrae are usually chosen as limits for fusion, the lower end vertebra can be excluded if the one above it is neutral [29]. Fusion down to L3 is achievable with an added mini-open retroperitoneal approach [30]. On AP radiograph, curves should measure up to $70^{\circ}$, and be flexible to at least $50 \%$ or reduced to $30^{\circ}$ on ipsilateral bending $[12,29,30,41]$. On lateral view, thoracic kyphosis (T5-T12) should be no greater than $40^{\circ}$ [41], since it is increased by the discectomies and compression technique used for reduction $[9,12,29]$. The ideal candidate is slender $(40-60 \mathrm{~kg})$, for easier portal placement and use, and tall, for ample space in the chest cavity and larger vertebral bodies for screw insertion [29].

Given the need for single-lung ventilation, pulmonary function testing is mandatory $[12,29]$. Poor pulmonary function, previous ipsilateral thoracic surgery, recurrent pneumonia and pulmonary tuberculosis are contraindications, as are osteopenia, 
seizure disorders and inability of the patient to comply with postoperative instructions due to the risk of implant loosening with the single-rod construct [12].

\section{Surgical technique}

A thoracotomy tray must be available and open, and the surgeon ready to perform an emergency thoracotomy if mandatory, because some complications such as massive bleeding can be difficult to treat through a thoracoscopic access [31].

Five or six portals are used, depending on the number of levels to be instrumented: three or four posterior portals for instrumentation and two anterior portals for scope insertion, spine exposure and discectomies. Once the pleura has been dissected to expose the spine circumferentially, the vertebral discs are removed, and the resulting spaces packed with hemostatic agent. Vertebral screws are inserted at a $10^{\circ}$ angle away from the spinal cord, purchasing both cortices, and accurate placement is confirmed with fluoroscopy. A stainlesssteel rod is cut to the appropriate length, measured with a balltip cable run through the screw heads. Bone graft is introduced between the endplates. The rod is then inserted successively over each screw head, applying compression with the next screw head at each segment before tightening the rod in place. A chest tube is inserted, and final X-rays are obtained to confirm curve correction and correct instrumentation [12].

Several types of bone graft may be used: rib autograft alone or augmented with demineralized bone matrix in a putty form, or morselized iliac crest autograft. A fibular strut or femoral ring allograft can also be added at the one or two distal levels of fusion to prevent excessive kyphosis in lower segments $[12,30,42]$.

The chest tube is typically removed on the second or third postoperative day. A custom-molded clamshell thoracolumbar orthosis (TLSO) is prescribed for 3 months postoperatively when the patient is out of bed $[12,30,32,42]$. Sports, bending and lifting activities are authorized after 3 to 6 months or radiographic evidence of solid anterior fusion [12].

\section{Results}

Initial results with TASF for AIS have been encouraging, despite a significant learning curve.

Compared to the standard posterior approach with pedicle screw fixation, TASF has similar radiographic results, patientbased clinical outcomes and complications rates in Lenke 1 curves up to $70^{\circ}$ with a normal or hypokyphotic spine. Advantages include decreased blood loss and transfusion rate, reduced total incision length, fewer fused levels, and preservation of approximately one distal level. Disadvantages include prolonged operative time, the need for a chest tube postoperatively and TLSO brace during 3 months, and slightly lesser improvement of pulmonary function $[9,41,43]$.
Patients are back to school after 2 to 4 weeks and can discontinue pain medication before 4 weeks [30]. Complications of TASF are primarily due to instrumentation failure (rod breakage), pseudarthrosis and pulmonary issues. Interestingly, deep wound infections are virtually non-existent after TASF, contrary to posterior fusion $[9,30,32,37,41,43-49]$.

A steep learning curve of 28 [46] or 30 [50] procedures has been described, during which deformity correction significantly increases and operative time significantly decreases. There does not, however, seem to be a significant difference in complication rates or blood loss throughout the operator's experience. Moreover, convening an experienced access surgeon may decrease this learning curve [31].

TASF is therefore a valid MIS option for AIS. This technically demanding procedure, with an acceptable complication rate including during the learning curve, is however restricted for thoracic curves (Lenke 1) with a normal or hypokyphoticspine and offers similar results for these patients when compared to the gold standard that is open posterior spine fusion. However, due to an increased degree of correction and lower risk of instrumentation failure associated with the modern posterior technique, most spine surgeons, including the proponents of this technique, have converted almost entirely to the posterior approach for thoracic AIS. Those still using TASF generally restrict it to patients with specific concerns regarding the appearance of a long posterior midline scar, and who would accept wearing a postoperative brace $[43,44]$. Hence a posterior MIS technique, with a wider range of indications and simplified instrumentation, could be more largely accepted by spine surgeons.

\section{Posterior Minimally Invasive Surgery for Adolescent Idiopathic Scoliosis}

The current gold standard for the surgical treatment of AIS is open posterior spinal instrumentation and fusion $[9,12,41]$. This approach creates a long midline incision spanning the vertebral levels to be fused. The appearance of the surgical scar seems to be an important factor in the patient's perception of the outcome [50,51]. In addition, this approach requires extensive detachment of most of the paravertebral muscle insertions from the spinous processes medially to the transverse processes laterally. This causes long-lasting paravertebral muscle injury and denervation, leading to persistent atrophy and decreased strength of trunk extension [52-60]. These injuries are related to retraction pressure, time, and extent of exposure [61].

Given the positive results of MIS techniques in adult spine pathologies, including deformities, the next logical step is to apply them to pediatric deformity surgery, AIS in particular. Yet many technical challenges are faced in this patient population $[15,62]$.

In contrast to adult degenerative scoliosis, AIS patients present with larger curves $\left(\geq 45^{\circ}\right)$, consequently more levels to 
instrument (7 to 13), three-dimensional deformity and usually significant vertebral rotation. In cases with double or triple major structural curves (Lenke 2, 3, 4 and 6), passing a rod with normal sagittal contour may be laborious. While the insertion of multiple percutaneous pedicle screws through separate stab incisions is routine in the adult patient population, this is not an option in AIS patients for multiple reasons. First, 14 to 26 screws would need to be inserted under fluoroscopic guidance, thereby increasing radiation exposure to both the surgeon and the young patient. The multitude of incisions would also probably be a major cosmetic concern in adolescents. Finally, surgical access would be a concern due to the small size of the incisions. Performing adequate facetectomy would be difficult, though crucial for fusion. The multiple reduction maneuvers required for the large deformities encountered in AIS (rod translation, rod de-rotation, in situ bending, direct vertebral rotation, and spine translation) would be limited by both the incision size and MIS instrumentation systems $[15,62]$.

In this setting, a specific MIS technique for AIS has been used since May 2008, based on three small cutaneous incisions with an underlying muscle splitting approach. It has been developed with the aim to limit incision length and soft tissue dissection, while allowing large facet osteotomies to promote fusion, insertion of pedicle screws with a free hand technique, and effortless introduction of contoured rods [15].

\section{Surgical technique}

The patient is installed prone on a radiolucent table, as for a conventional posterior approach. After prepping and draping, fluoroscopy is used to determine the length and localization of 3 separated midline skin incisions (Figure 1). Fluoroscopy use is limited to the planning of the skin incisions [14].

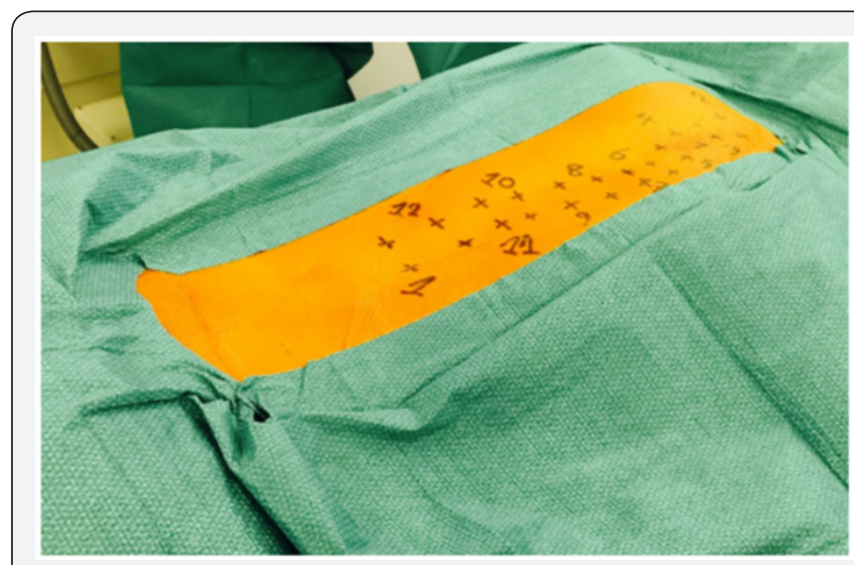

Figure 1: After prepping and draping, the levels of the pedicles of the vertebrae to be instrumented and fused are marked using fluoroscopy, to allow for planning of the 3 separate skin incisions. The 3 incisions will be made on the median line and centered over the pedicles of the vertebrae to be instrumented. Right side of the picture: cephalad.

The skin is then undermined laterally to allow for paramedian extraperiosteal fascial incisions on each side of the spine. A blunt muscle sparing approach is used down to the facet joints in the lumbar spine, and to the transverse processes in the thoracic spine. This is similar to the paraspinal sacrospinalis-splitting approach described by Wiltse for the lumbar spine [63-65]. Posterior elements are uncovered using electrocoagulation, from the basis of the lamina to the transverse processes. Wide facetectomies are performed. The pedicles are cannulated using the free hand technique [66] and marked with pedicle markers. The facet joints are then decorticated using a high-speed burr. Bone graft (a mixture of autograft from the facetectomies and freeze-dried allograft) is applied before definitive instrumentation (Figure 2).

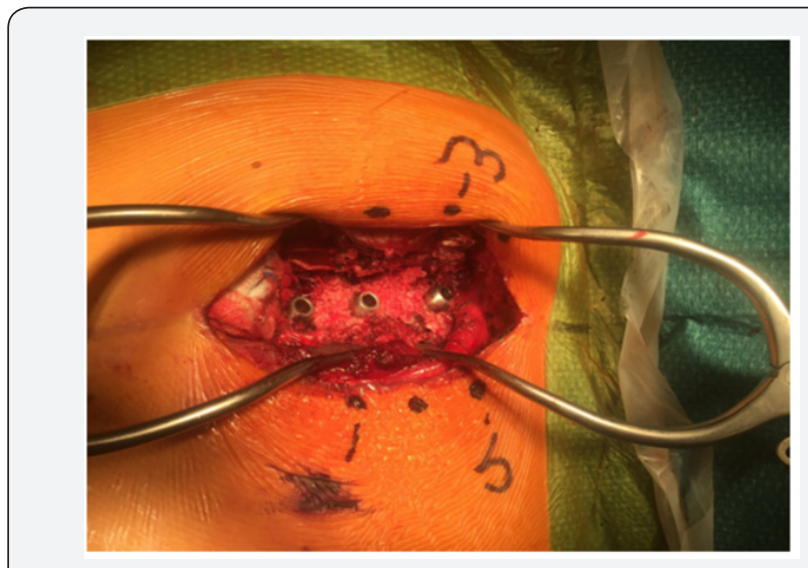

Figure 2: Intraoperative view showing the custom-made pedicle markers inserted on the right side of the patient at T2, T3 and T4. The posterior elements have been decorticated and bone graft has been laid down. Right side of the picture: cephalad.

Three segments are instrumented, one per skin incision (Figure 3). The facet joints located between skin incisions are not instrumented, but facetectomies, decortications and bone grafting are still performed by mobilizing the skin and soft tissues.

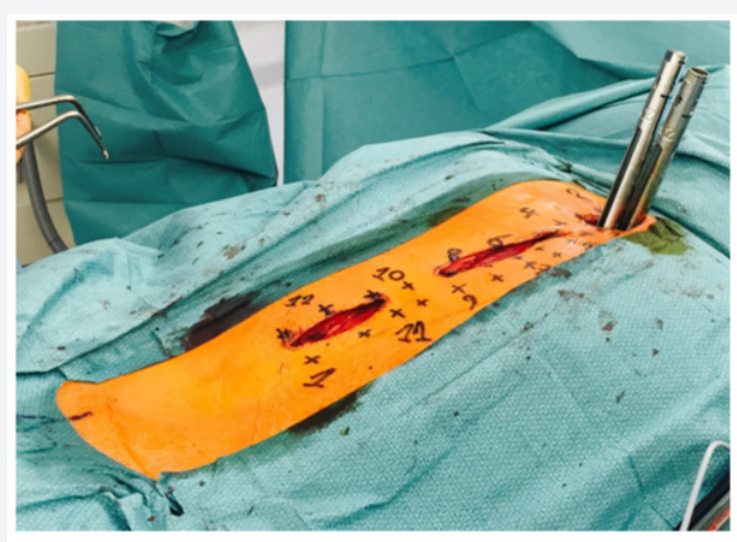

Figure 3: Intraoperative view showing the 3 posterior skin incisions, centered over the three segments of instrumentation. The prepared pedicles remain located with pedicle markers (not visible deeply in the wounds). Facetectomies and decortication have been performed, and bone graft has been applied. Right side of the picture: cephalad

Cannulated pedicle screws, already connected to reduction tubes, are then exchanged with the cannulated pedicle markers using a guide wire (Figure 4). Monoaxial screws are placed in the 
convexity of the major curve. The remaining screws are polyaxial. Some alternate reduction screws with extended tabs and MIS screws with open connectors (reduction tubes) between levels $[15,62]$. Others [67] favor MIS screws with reduction tubes at every instrumented level, in order to facilitate insertion of the rod and apical derotation during deformity reduction.

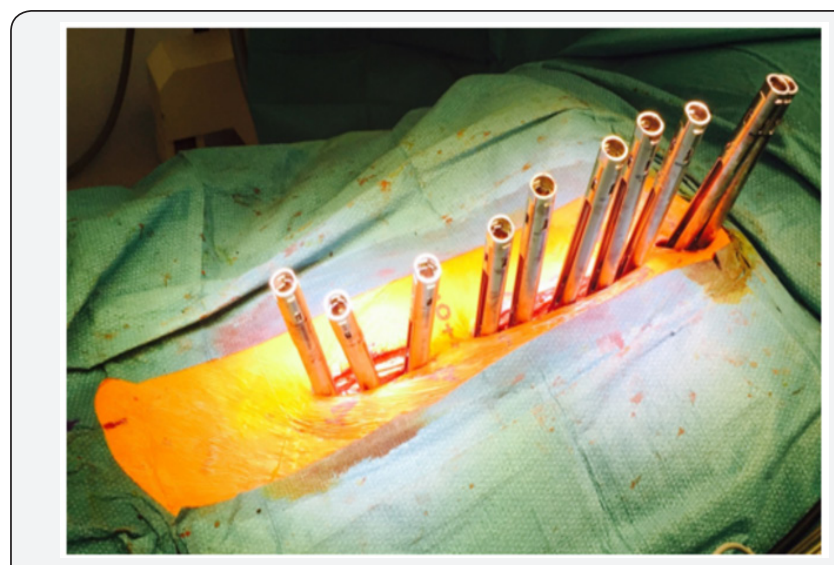

Figure 4: Cannulated pedicle screws, mounted with MIS reduction tubes, have been exchanged with the pedicle markers on the right side of the patient. Right side of the picture: cephalad.

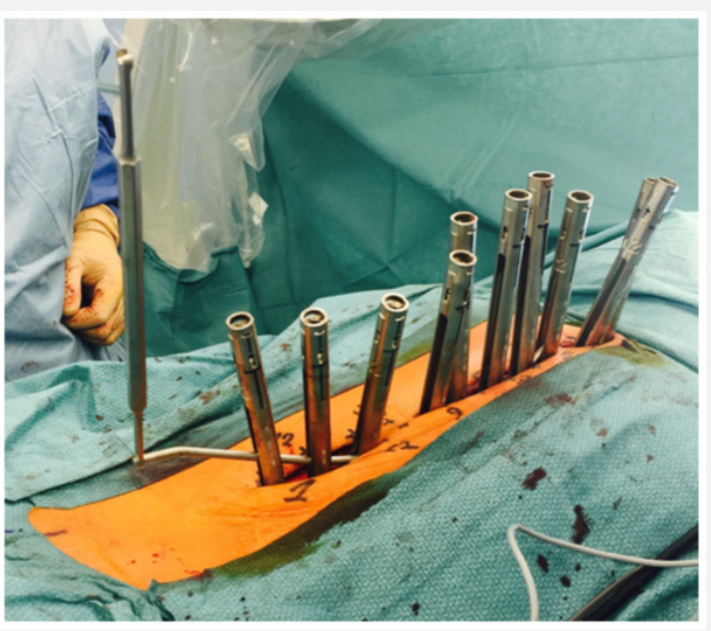

Figure 5: The contoured rod is inserted first on the right side of the patient for a right thoracic curve, and passed from distal to proximal, using the slots of the MIS reduction tubes. Note on the left side of the picture the hexagonal wrench used to control rod rotation. Right side of the picture: cephalad.

Two $5.5 \mathrm{~mm}$ cobalt chrome rods are cut to the measured length and contoured with the appropriate sagittal profile. The convex side rod is introduced first. It is passed below the fascia of the cutaneous bridge under direct visualization, then through the slots of the reduction tubes. Inserting the rod from caudal to cephalad avoids conflict with the patient's head (Figure 5), but some argue that the opposite direction offers increased safety due to the fact that the orientation of the overlapping laminae and facets in the thoracic spine tends to prevent accidental penetration of the spinal canal [15,62]. Rod derotation and a gradual spine-to-rod reduction technique are used to correct most of the deformity. The rod is secured using set screws, and direct apical segmental derotation is performed. The pedicle markers on the concave side are finally exchanged for pedicle screws. The second concave rod is overcontoured in the sagittal plane to allow for further deformity correction in the transverse plane.It is then also inserted from distal to proximal.

\section{Results in the current literature}

There is currently limited data on the application of posterior MIS in pediatric spine deformity, despite the fact that it may have the potential to significantly improve perioperative morbidity.

Samdani et al. [68] first reported their results using posterior MIS technique to treat AIS patients. Their surgical technique varies slightly with the one previously described by the fact that they used a single midline skin incision instead of 3 separated incisions. This allows for increased implant density with bilateral pedicle screws at every level fused. Fifteen patients were operated with a mean age of 14.1 years (11-16) and an average follow-up of 8 months (2-35). The preoperative major curve Cobb angle was on an average $54^{\circ}(45-82)$ and was corrected to a mean of $18^{\circ}(9-35)$. This represents an average correction of $67 \%$. In the sagittal plane, thoracic kyphosis decreased from $31^{\circ}(18-47)$ to $26^{\circ}(15-34)$. The mean estimated blood loss (EBL) was $254 \mathrm{ml}$ (100-672) and the average operative time (ORT) was 470 minutes (236-662). Regarding complications, one patient presented with a pullout of the proximal screws at 8 months postoperatively and required revision.

Miyanji et al. [14] reported their results comparing a three-incision posterior MIS technique with standard open posterior surgery for AIS. Sixteen patients treated with MIS were matched for age, sex, curve type and size to 16 patients treated with conventional open surgery. There was no significant difference between MIS and open surgery in terms of major Cobb angle correction ( $63 \% \pm 13$ versus $68 \% \pm 8$ respectively) or postoperative thoracic kyphosis $\left(21^{\circ} \pm 9\right.$ versus $17^{\circ} \pm 5$ respectively). In the MIS group, EBL was significantly lower ( $277 \mathrm{ml} \pm 105$ versus $388 \mathrm{ml} \pm 158$ ), ORT was significantly longer ( $444 \mathrm{~min} \pm 89$ versus $350 \mathrm{~min} \pm 76$ ) and hospital stay (LOS) was significantly shorter ( 4.63 days \pm 0.96 versus 6.19 days \pm 1.68 ) when compared to open surgery.

In a retrospective comparative study, Sarwahi et al. [62] compared 7 MIS patients to 15 open posterior patients with 2 years of follow-up data. MIS was associated with a longer median ORT despite a decreased implant density. There was no significant difference in EBL, EBL per fixation point, amount of fluids administered, number of intensive care unit days, LOS, time to mobilization, visual analog pain scores, patient-controlled analgesia days, deformity correction, screw placement accuracy, fusion rate or complications. There was a lower incidence of postoperative anemia and transfusion in the MIS group. The difference in ORT should be interpreted with caution, given the fact that this small series of 7 patients was considered the senior 
surgeon's learning curve. Considering what we know from TASF $[45,49]$ and another series on posterior MIS [67], this most likely represents the very beginning of the learning curve.

It is worth noting that LOS is influenced by numerous factors, among which postoperative management seems to play an important role. Postoperative admission of AIS patients to a general ward, rather than an intensive care unit, has been correlated with a reduced LOS and decreased analgesic medication usage [69]. The use of an early discharge pathway has been associated with a $48 \%$ shorter LOS after posterior spinal fusion for AIS [70-72]. The two comparative studies mentioned above did not specifically describe their recovery protocol, nor did they specify whether postoperative management was any different between MIS and open surgery groups [14,62].

The largest series to date is a retrospective analysis on prospectively collected data by de Bodman et al. [67]. It reported results from the first 70 consecutive patients who underwent posterior MIS for AIS by a single surgeon, with a mean age of 15 years \pm 4.5 and a male to female ratio of 8:62. Preoperative major Cobb angle averaged $58.9^{\circ} \pm 12.6$ and was significantly corrected to $17.7^{\circ} \pm 10.2$ (a $69 \% \pm 20$ curve correction). Thoracic kyphosis, as evaluated between T2-T12 and T5-T12, was also significantly improved by $18 \%$ and $24 \%$ respectively.

Perioperative (30 days) complication rate was $4.3 \%$, with 3 complications in 3 patients: 1 subcutaneous hematoma, 1 deep venous thrombosis, and 1 pneumothorax. Five (7.1\%) additional complications occurred in 5 patients at an overall mean followup of 2 years \pm 1.4 : 1 superficial wound infection, 1 suture granuloma, and 3 delayed deep surgical site infections (4.3\%). These 3 delayed deep surgical site infections were encountered among the first 19 patients treated with MIS.

ORT averaged $337 \mathrm{~min} \pm 121$. ORT per level showed a steep decrease over the first 25 cases, then stabilized to a plateau of $25 \mathrm{~min} \pm 5$. The mean EBL was $346 \mathrm{ml} \pm 175$, and EBL per level was $36 \mathrm{ml} \pm 14$. No allogeneic blood transfusions were needed. EBL also significantly decreased with increasing experience with the surgical technique. The average LOS was 4.6 days \pm 0.8 . The average number of screws used was $18.6 \pm 4$.1. The mean number of levels fused was $11.2 \pm 4.9$, representing an overall average of $30 \pm 15.1$ minutes of ORT per level.

These results indicate that MIS for AIS is associated with a significant correction of spine deformity in frontal and sagittal planes, together with low EBL and short LOS. The perioperative complication rate compares well with the standard open technique, as reported by large morbidity databases [1]. The rate of delayed surgical site infection, however, was unusually high, with reported rates after open posterior surgery ranging from $0.9 \%$ to $3 \%[1,73-76]$. The duration of surgery is significantly correlated with the rate of multiple complications [77]. Given the reduction in ORT over the first 25 cases in this series, the high rate of delayed infection could be due to a learning curve effect.
Taken together, the limited available data suggest that the use of posterior MIS for AIS is associated with deformity correction and complication rates similar to open posterior spinal fusion, with potential benefits related to a less traumatizing exposure, low blood loss and a diminished length of hospital stay. However, these encouraging results are obtained at the expense of an increased surgical time, which could be related, at least partially, to a learning curve effect.

\section{Conclusion}

Posterior MIS for AIS is associated with low blood loss and decreased length of hospital stay, while offering similar power of deformity correction in the frontal and sagittal planes, when compared with standard open posterior technique. However, operative time is significantly increased, at least during the surgeon's learning curve. The longer-term safety of this procedure needs to be documented in larger studies with a minimum of 2 and 5 years of follow-up, before recommending its routine use. Finally, the most important challenge will probably be to offer this type of surgery to the frailest pediatric spine deformity patients, without further increasing the significant complication rate associated with the surgical treatment of neuromuscular scoliosis.

\section{References}

1. Reames DL, Smith JS, Fu KM, Polly DW, Ames CP, et al. (2011) Complications in the surgical treatment of 19,360 cases of pediatric scoliosis: a review of the Scoliosis Research Society Morbidity and Mortality database. Spine (Phila Pa 1976) 36(18):1484-1491.

2. Pehrsson K, Larsson S, Oden A, Nachemson A (1992) Long-term followup of patients with untreated scoliosis. A study of mortality, causes of death, and symptoms. Spine (Phila Pa 1976) 17(9):1091-1096

3. Pehrsson K, Nachemson A, Olofson J, Ström K, Larsson S (1992) Respiratory failure in scoliosis and other thoracic deformities. A survey of patients with home oxygen or ventilator therapy in Sweden. Spine (Phila Pa 1976) 17(6):714-718.

4. Weinstein SL, Dolan LA, Spratt KF, Peterson KK, Spoonamore MJ, et al. (2003) Health and function of patients with untreated idiopathic scoliosis: a 50-year natural history study. JAMA 289(5):559-567.

5. Saltikov JB, Weiss HR, Chockalingam N, Taranu R, Srinivas S, etal. (2015) Surgical versus non-surgical interventions in people with adolescent idiopathic scoliosis. Cochrane Database Syst Rev 4: CD010663.

6. Maruyama T, Takeshita K (2008) Surgical treatment of scoliosis: a review of techniques currently applied. Scoliosis 3:6.

7. Sy N, Bettany-Saltikov J, Moramarco M (2016) Evidence for Conservative Treatment of Adolescent Idiopathic Scoliosis - Update 2015 (MiniReview). CurrPediatr Rev 12(1):6-11.

8. Weinstein SL, Dolan LA, Wright JG, Dobbs MB (2013) Effects of bracing in adolescents with idiopathic scoliosis. N Engl J Med 369:1512-1521.

9. Newton PO, Marks MC, Bastrom TP,Betz R, Clements D, et al. (2013) Surgical treatment of Lenke 1 main thoracic idiopathic scoliosis: results of a prospective, multicenter study. Spine (Phila Pa 1976) 38(4):328-338.

10. Lonner BS (2007) Emerging minimally invasive technologies for the management of scoliosis. Orthop Clin North Am 38(3):431-440. 
11. Lenke LG, Bridwell KH, Blanke K, Baldus C, Weston J (1998) Radiographic results of arthrodesis with Cotrel-Dubousset instrumentation for the treatment of adolescent idiopathic scoliosis. A five to ten-year followup study. J Bone Joint Surg Am 80(6):807-814

12. Lonner BS, Kondrachov D, Siddiqi F, Hayes V, Scharf C (2007) Thoracoscopic spinal fusion compared with posterior spinal fusion for the treatment of thoracic adolescent idiopathic scoliosis. Surgical technique. J Bone Joint Surg Am 89 Suppl 2 Pt.1: 142-156.

13. Richards BS, Herring JA, Johnston CE, Birch JG, Roach JW (1994) Treatment of adolescent idiopathic scoliosis using Texas Scottish Rite Hospital instrumentation. Spine (Phila Pa 1976) 19(14):1598-1605.

14. Miyanji F, Samdani A, Ghag A, Marks M, Newton PO (2013) Minimally invasive surgery for AIS: en early prospective comparisonwith standard open surgery. J Spine 1:1-4.

15. Sarwahi V, Wollowick AL, Sugarman EP, Horn JJ, Gambassi M, et al. (2011) Minimally invasive scoliosis surgery: an innovative technique in patients with adolescent idiopathic scoliosis. Scoliosis 6:16.

16. Wang MY (2013) Improvement of sagittal balance and lumbar lordosis following less invasive adult spinal deformity surgery with expandable cages and percutaneous instrumentation. J Neurosurg Spine 18(1):412 .

17. Smith JS, Klineberg E, Lafage V, Shaffrey CI, Schwab F, et al. (2016) Prospective multicenter assessment of perioperative and minimum 2-year postoperative complication rates associated with adult spinal deformity surgery. J Neurosurg Spine 25(1): 1-14.

18. Pateder DB, Gonzales RA, Kebaish KM, Cohen DB, Chang JY, et al. (2008) Short-term mortality and its association with independent risk factors in adult spinal deformity surgery. Spine (Phila Pa 1976) 33(11):12241228.

19. Anand N, Baron EM, Khandehroo B (2014) Is circumferential minimally invasive surgery effective in the treatment of moderate adult idiopathic scoliosis? Clin OrthopRelat Res 472(6):1762-1768.

20. Anand N, Baron EM, Khandehroo B, Kahwaty S (2013) Long-term 2- to 5-year clinical and functional outcomes of minimally invasive surgery for adult scoliosis. Spine (Phila Pa 1976) 38(18):1566-1575.

21. Anand N, Baron EM, Thaiyananthan G, Khalsa K, Goldstein TB (2008) Minimally invasive multilevel percutaneous correction and fusion for adult lumbar degenerative scoliosis: a technique and feasibility study. J Spinal Disord Tech 21(7):459-467.

22. Deukmedjian AR, Ahmadian A, Bach K, Zouzias A, Uribe JS (2013) Minimally invasive lateral approach for adult degenerative scoliosis: lessons learned. Neurosurg Focus 35(2):E4.

23. Haque RM, Mundis GM, Ahmed Y, El Ahmadieh TY, Wang MY, et al (2014) Comparison of radiographic results after minimally invasive, hybrid, and open surgery for adult spinal deformity: a multicenter study of 184 patients. Neurosurg Focus 36(5):E13.

24. Haque RM, Uddin OM, Ahmed Y, El Ahmadieh TY, Hashmi SZ, et al. (2014) "Push-Through" Rod Passage Technique for the Improvement of Lumbar Lordosis and Sagittal Balance in Minimally Invasive Adult Degenerative Scoliosis Surgery. J Spinal Disord Tech.

25. Park P, Wang MY, Lafage V, Nguyen S, Ziewacz J, et al. (2015) Comparison of two minimally invasive surgery strategies to treat adult spinal deformity. J Neurosurg Spine 22(4):374-380.

26. Uddin OM, Haque R, Sugrue PA, Ahmed YM, El Ahmadieh TY, et al. (2015) Cost minimization in treatment of adult degenerative scoliosis. J Neurosurg Spine 23(6):798-806.

27. Uribe JS, Deukmedjian AR, Mummaneni PV, Fu KM, Mundis GM, et al. (2014) Complications in adult spinal deformity surgery: an analysis of minimally invasive, hybrid, and open surgical techniques. Neurosurg Focus 36(5):E15.

28. Kanter AS, Tempel ZJ, Ozpinar A, Okonkwo DO (2016) A Review of Minimally Invasive Procedures for the Treatment of Adult Spinal Deformity. Spine (Phila Pa 1976) 41 Suppl 8:S59-S65.

29. Sucato DJ (2003) Thoracoscopic anterior instrumentation and fusion for idiopathic scoliosis. J Am AcadOrthop Surg 11(4):221-227.

30. Norton RP, Patel D, Kurd MF, et al. (2007) The use of thoracoscopy in the management of adolescent idiopathic scoliosis. Spine Phila Pa 1976 32:2777-2785.

31. Crawford AH (2005) Anterior surgery in the thoracic and lumbar spine: endoscopic techniques in children. Instr Course Lect 54:567-576.

32. Picetti GD, Ertl JP, Bueff HU (2001) Endoscopic instrumentation, correction, and fusion of idiopathic scoliosis. Spine J 1(3):190-197.

33. Lenke LG, Betz RR, Clements D, Merola A, Haher T, et al. (2002) Curve prevalence of a new classification of operative adolescent idiopathic scoliosis: does classification correlate with treatment? Spine (Phila Pa 1976) 27(6):604-611

34. Lenke LG, Betz RR, Harms J, Bridwell KH, Clements DH, et al. (2001) Adolescent idiopathic scoliosis: a new classification to determine extent of spinal arthrodesis. J Bone Joint Surg Am 83-A(8):1169-1181.

35. Betz RR, Harms J, Clements DH, Lenke LG, Lowe TG, et al. (1999) Comparison of anterior and posterior instrumentation for correction of adolescent thoracic idiopathic scoliosis. Spine (Phila Pa 1976) 24(3):225-239.

36. Kishan S, Bastrom T, Betz RR, Lenke LG, Lowe TG, et al. (2007) Thoracoscopic scoliosis surgery affects pulmonary function less than thoracotomy at 2 years postsurgery. Spine Phila Pa 1976 32(4):453458.

37. Newton PO, Marks M, Faro F, Betz R, Clements D, et al. (2003) Use of video-assisted thoracoscopic surgery to reduce perioperative morbidity in scoliosis surgery. Spine (Phila Pa 1976) 28(20):S249-S254.

38. Ritzman TF, Upasani VV, Pawelek JB, Betz RR, Newton PO (2008) Return of shoulder girdle function after anterior versus posterior adolescent idiopathic scoliosis surgery. Spine (Phila Pa 1976) 33(20):2228-2235.

39. Lonner BS, Auerbach JD, Estreicher MB, Betz RR, Crawford AH, et al. (2009) Pulmonary function changes after various anterior approaches in the treatment of adolescent idiopathic scoliosis. J Spinal Disord Tech 22(8):551-558.

40. Faro FD, Marks MC, Newton PO, Blanke K, Lenke LG (2005) Perioperative changes in pulmonary function after anterior scoliosis instrumentation: thoracoscopic versus open approaches. Spine (Phila Pa 1976) 30(9):1058-1063.

41. Lonner BS, Auerbach JD, Estreicher M, Milby AH, Kean KE (2009) Video-assisted thoracoscopic spinal fusion compared with posterior spinal fusion with thoracic pedicle screws for thoracic adolescent idiopathic scoliosis. J Bone Joint Surg Am 91(2):398-408.

42. Newton PO, Upasani VV, Lhamby J,Ugrinow VL, Pawelek JB, et al. (2009) Surgical treatment of main thoracic scoliosis with thoracoscopic anterior instrumentation. Surgical technique. J Bone Joint Surg Am 91 Suppl 2:233-248.

43. Lee CS, Park SJ, Chung SS, Kang KC, Jung CH, et al. (2013) A comparative study between thoracoscopic surgery and posterior surgery using allpedicle-screw constructs in the treatment of adolescent idiopathic scoliosis. J Spinal Disord Tech 26(6):325-533.

44. Lonner BS, Kondrachov D, Siddiqi F, Hayes V, Scharf C (2006) Thoracoscopic spinal fusion compared with posterior spinal fusion for 
the treatment of thoracic adolescent idiopathic scoliosis. J Bone Joint Surg Am 88: 1022-1034.

45. Lonner BS, Scharf C, Antonacci D, et al. (2005) The learning curve associated with thoracoscopic spinal instrumentation. Spine Phila $\mathrm{Pa}$ 1976 30:2835-2840.

46. Newton PO, Parent S, Marks M, Pawelek J (2005) Prospective evaluation of 50 consecutive scoliosis patients surgically treated with thoracoscopic anterior instrumentation. Spine (Phila Pa 1976) 30(17 Suppl): S100-S109.

47. Wong HK, Hee HT, Yu Z, Wong D (2004) Results of thoracoscopic instrumented fusion versus conventional posterior instrumented fusion in adolescent idiopathic scoliosis undergoing selective thoracic fusion. Spine (Phila Pa 1976) 29(18): 2031-2038.

48. Newton PO, Upasani VV, Lhamby J,Ugrinow VL, Pawelek JB, et al. (2008) Surgical treatment of main thoracic scoliosis with thoracoscopic anterior instrumentation. a five-year follow-up study. J Bone Joint Surg Am 90(10): 2077-2089.

49. Newton PO, Shea KG, Granlund KF (2000) Defining the pediatric spinal thoracoscopy learning curve: sixty-five consecutive cases. Spine (Phila Pa 1976) 25(8):1028-1035.

50. Buchanan R, Birch JG, Morton AA, Browne RH (2003) Do you see what I see? Looking at scoliosis surgical outcomes through orthopedists' eyes. Spine Phila Pa 1976 28(24): 2700-2704.

51. Misterska E, Glowacki M, Harasymczuk J (2011) Assessment of spinal appearance in female patients with adolescent idiopathic scoliosis treated operatively. Med Sci Monit 17(7): CR404-CR410.

52. Kawaguchi Y, Matsui H, Tsuji H (1994) Back muscle injury after posterior lumbar spine surgery. Part 2: Histologic and histochemical analyses in humans. Spine (Phila Pa 1976) 19(22): 2598-2602.

53. Kawaguchi Y, Matsui H, Tsuji H (1994) Back muscle injury after posterior lumbar spine surgery. Part 1: Histologic and histochemical analyses in rats. Spine (Phila Pa 1976) 19:2590-2597.

54. Kawaguchi Y, Yabuki S, Styf J, Olmarker K, Rydevik B, et al. (1996) Back muscle injury after posterior lumbar spine surgery. Topographic evaluation of intramuscular pressure and blood flow in the porcine back muscle during surgery. Spine (Phila Pa 1976) 21(22): 2683-2688.

55. Kim DY, Lee SH, Chung SK, Lee HY (2005) Comparison of multifidus muscle atrophy and trunk extension muscle strength: percutaneous versus open pedicle screw fixation. Spine (Phila Pa 1976) 30(1): 123129.

56. Macnab I, Cuthbert H, Godfrey CM (1977) The incidence of denervation of the sacrospinales muscles following spinal surgery. Spine Phila $\mathrm{Pa}$ 1976 2(4): 294-298.

57. Mayer TG, Vanharanta H, Gatchel RJ, Mooney V, Barnes D, et al. (1989) Comparison of CT scan muscle measurements and isokinetic trunk strength in postoperative patients. Spine (Phila Pa 1976) 14(1): 33-36.

58. Rantanen J, Hurme M, Falck B,Alaranta H, Nykvist F, et al. (1993) The lumbar multifidus muscle five years after surgery for a lumbar intervertebral disc herniation. Spine (Phila Pa 1976) 18(5): 568-574.

59. Styf JR, Willen J (1998) The effects of external compression by three different retractors on pressure in the erector spine muscles during and after posterior lumbar spine surgery in humans. Spine (Phila Pa 1976) 23(3): 354-358.

60. Weber BR, Grob D, Dvorak J, Muntener M (1997) Posterior surgical approach to the lumbar spine and its effect on the multifidus muscle. Spine (Phila Pa 1976) 22(15): 1765-1772.
61. Kawaguchi Y, Matsui H, Tsuji H (1996) Back muscle injury after posterior lumbar spine surgery. A histologic and enzymatic analysis. Spine (Phila Pa 1976) 21(8): 941-944.

62. Sarwahi V, Horn JJ, Kulkarni PM, Wollowick AL, Lo Y, et al. (2016) Minimally Invasive Surgery in Patients with Adolescent Idiopathic Scoliosis: Is it Better than the Standard Approach? A 2-Year Follow-Up Study. Clin Spine Surg 29(8): 331-340.

63. Vialle R, Court C, Khouri N, Olivier E, Miladi L, et al. (2005) Anatomical study of the paraspinal approach to the lumbar spine. Eur Spine J 14(4): 366-371.

64. Wiltse LL (1973) The paraspinal sacrospinalis-splitting approach to the lumbar spine. Clin OrthopRelat Res 91: 48-57.

65. Wiltse LL, Bateman JG, Hutchinson RH, Nelson WE (1968) The paraspinal sacrospinalis-splitting approach to the lumbar spine. J Bone Joint Surg Am 50(5): 919-926.

66. Kim YJ, Lenke LG, Bridwell KH, Cho YS, Riew KD (2004) Free hand pedicle screw placement in the thoracic spine: is it safe? Spine (Phila Pa 1976) 29(3): 333-342.

67. de Bodman C, Miyanji F, Borner B, Zambelli PY, Racloz G, et al. (2017) Minimally invasive surgery for adolescent idiopathic scoliosis: correction of deformity and peri-operative morbidity in 70 consecutive patients. Bone Joint J 99-B(12): 1651-1657.

68. Samdani AF, Asghar J, Miyanji F, et al. (2011) Minimally invasive treatment of pediatric spinal deformity. Semin Spine Surg 23: 72-75.

69. Shan LQ, Skaggs DL, Lee C, Kissinger C, Myung KS (2013) Intensive care unit versus hospital floor: a comparative study of postoperative management of patients with adolescent idiopathic scoliosis. J Bone Joint Surg Am 95(7): e40.

70. Fletcher ND, Andras LM, Lazarus DE, Owen RJ, Geddes BJ, et al. (2015) Use of a Novel Pathway for Early Discharge Was Associated With a 48\% Shorter Length of Stay After Posterior Spinal Fusion for Adolescent Idiopathic Scoliosis. J Pediatr Orthop 37(2): 92-97.

71. Fletcher ND, Shourbaji N, Mitchell PM, Oswald TS, Devito DP, et al. (2014) Clinical and economic implications of early discharge following posterior spinal fusion for adolescent idiopathic scoliosis. J Child Orthop 8(3): 257-263.

72. Gornitzky AL, Flynn JM, Muhly WT, Sankar WN (2016) A Rapid Recovery Pathway for Adolescent Idiopathic Scoliosis That Improves Pain Control and Reduces Time to Inpatient Recovery After Posterior Spinal Fusion. Spine Deform 4(4): 288-295.

73. Coe JD, Arlet V, Donaldson W, Berven S, Hanson DS, et al. (2006) Complications in spinal fusion for adolescent idiopathic scoliosis in the new millennium. A report of the Scoliosis Research Society Morbidity and Mortality Committee. Spine (Phila Pa 1976) 31(3): 345-349.

74. Rihn JA, Lee JY, Ward WT (2008) Infection after the surgical treatment of adolescent idiopathic scoliosis: evaluation of the diagnosis, treatment, and impact on clinical outcomes. Spine (Phila Pa 1976) 33(3): 289-294.

75. Ho C, Sucato DJ, Richards BS (2007) Risk factors for the development of delayed infections following posterior spinal fusion and instrumentation in adolescent idiopathic scoliosis patients. Spine (Phila Pa 1976) 32(20): 2272-2277.

76. Di Silvestre M, Bakaloudis G, Lolli F, Giacomini S (2011) Late-developing infection following posterior fusion for adolescent idiopathic scoliosis. Eur Spine J 20(Suppl 1): S121-S127.

77. Hod-Feins R, Abu-Kishk I, Eshel G, Barr Y, Anekstein Y, et al. (2007) Risk factors affecting the immediate postoperative course in pediatric scoliosis surgery. Spine (Phila Pa 1976) 32(21): 2355-2360. 
This work is licensed under Creative Commons Attribution 4.0 License

DOI: $10.19080 / J H N S S .2018 .03 .555608$
Your next submission with Juniper Publishers will reach you the below assets

- Quality Editorial service

- Swift Peer Review

- Reprints availability

- E-prints Service

- Manuscript Podcast for convenient understanding

- Global attainment for your research

- Manuscript accessibility in different formats ( Pdf, E-pub, Full Text, Audio)

- Unceasing customer service

Track the below URL for one-step submission https://juniperpublishers.com/online-submission.php 